\title{
Genetic and Epigenetic Markers to Identify High Risk Patients for Multiple Early Gastric Cancers after Treatment with Endoscopic Mucosal Resection
}

\author{
Mayumi Fukuda ${ }^{1,2}$, Hiroshi Yokozaki ${ }^{2}$, Masatsugu Shiba ${ }^{1}$, Kazuhide Higuchi ${ }^{1 * *}$, \\ and Tetsuo Arakawa ${ }^{1}$ \\ 'Department of Gastroenterology, Osaka City University Graduate School of Medicine, 1-4-3 Asahi-machi, \\ Abeno-ku, Osaka 545-8585, Japan \\ ${ }^{2}$ Division of Surgical Pathology, Department of Biomedical Informatics, Kobe University Graduate School of \\ Medicine, 7-5-1 Kusunoki-cho, Chuo-ku, Kobe 650-0017, Japan
}

Received 19 October, 2006; Accepted 25 October, 2006

\begin{abstract}
Summary The development of multiple gastric cancer is a major problem after the endoscopic resection of the first early gastric cancer. To find out markers to identify high risk patients, we analyzed the microsatellite instability (MSI) status and hypermethylation of tumor-related genes in multiple gastric cancers. Sixty-four adenocarcinomas resected by endoscopy, including 32 early solitary gastric cancers (SGCs) from 32 patients and 32 multiple gastric cancers (MGCs) from 14 patients, were employed. We analyzed MSI and the methylation status of promoter regions of the $h M L H 1, M G M T, p 16$ and E-cadherin using methylation-specific Polymerase Chain Reaction. Expression levels of $h M L H 1$ were examined by immunohistochemistry. MSI $(+)$ was detected in 5 of the $14(35.7 \%)$ patients with MGCs, and in only 3 of the 32 patients $(9.3 \%)$ with SGCs. Significant differences were observed between the 2 groups $(p<0.001)$. Hypermethylation of $h M L H 1$ was more frequently detected in MGCs than in SGCs $(p<0.01)$, whereas significant difference was not observed in the frequency of $M G M T$, p16 or E-cadherin promoter methylation between the 2 groups. In conclusion, our results indicate that inactivation of $h M L H 1$ through promoter hypermethylation may be involved in the development of multiple gastric cancers following the MSI pathway.
\end{abstract}

Key Words: multiple gastric cancer, microsatellite instability, CpG island methylation

\section{Introduction}

Due to advances in endoscopic therapeutic techniques such as mucosal resection, gastric cancers have usually been treated at an early stage. If it is completely resected by histology, gastric cancer does not recur at the treated scar.

\footnotetext{
*To whom correspondence should be addressed.

Tel: 81-6-6645-3811 Fax: 81-6-6646-3413

E-mail: khiguchi@med.osaka-cu.ac.jp
}

Different from surgery, almost all gastric mucosa remains with malignant potential. Multiple gastric cancers are observed in approximately $3.7-5.7 \%$ of all patients with gastric cancer $[1,2]$. Uemura et al. [3] reported that the rates of metachronous multiple gastric cancer were $9 \%$ during three years after the resection of the first gastric cancer. Endoscopists should carefully follow the patients treated with endoscopic resection for gastric cancers in order to find metachronous multiple gastric cancers. It is clinically and economically important to narrow the number of patients followed by the high risk factors. However, it is not well-known what these 
risk factors are or the predictive factors for the development of metachronous multiple gastric cancers.

Microsatellite instability (MSI) due to defects in mismatch repair genes such as $h M L H 1$ and $h M S H 2$ is now widely recognized as an important mechanism in tumorigenesis [46. In addition, epigenetic silencing of tumor suppressor or tumor-related genes and mismatch repair genes, due to hypermethylation of cytosine guanine dinucleotides $(\mathrm{CpG})$ sites in the 5' promoter resions, has emerged recently as one of the pivotal genetic alterations in cancer development [7, 8]. Several reports have been published about methylation of various genes, including $h M L H 1, \mathrm{O}^{6}$-methylguanine DNA methylyransferase (MGMT), E-cadherin and p16, in chronic gastritis, intestinal metaplasia and adenomas to carcinomas of the stomach [9-13]. However, few reports have described about the correlation between the presence of MSI and DNA hypermethylation in multiple gastric cancers [14-16]. In order to find genetic and epigenetic markers to identify high risk patients for multiple early gastric cancers after treatment with endoscopic mucosal resection (EMR), we analyzed the MSI status and hypermethylation of multiple tumor-related genes in these patients comparing single gastric cancer with synchronous and metachronous multiple gastric cancers.

\section{Materials and Methods}

\section{Patients}

Sixty-four adenocarcinomas, including 32 solitary tumors from 32 patients and 32 multiple tumors from 14 patients treated with endoscopic mucosal resection at the Osaka City University Hospital between 1993 and 2002 were studied. Written informed concent was obtained from all patients. These patients received follow-up esophagogastro-duodenoscopy at 1 month, 3 months and then every 6 months after the first cancer treatment. The mean age of the patients with a single gastric cancer and with synchronous and metachronous multiple gastric cancers was 67.1 and 71.5 years, respectively. The male to female ratios of these groups were 21/11 and 12/2, respectively. Active Helicobacter pylori (H. pylori) infection was identified by histology, serology test for $H$. pylori antibody and urea breath test. Active $H$. pylori infection was detected in 14 patients $(43.8 \%)$ and in 8 patients $(57.1 \%)$, respectively.

\section{DNA extraction}

Tissue sections, $4 \mu \mathrm{m}$ in thickness, were cut from formalinfixed and paraffin-embedded blocks were placed on a glass slide and stained with hematoxylin and eosin. These tissue sections were then dehydrated in graded ethanol solutions and dried. Cancerous and normal tissues on the slide were carefully dissected using tooth picks, separately, using the serial haematoxylin-eosin stained sections under the micro- scope as a reference. DNA was extracted from the tissues with $50 \mu \mathrm{l}$ of extraction buffer $(100 \mathrm{mM}$ Tris- $\mathrm{HCl}, \mathrm{pH} 7.8$, $2 \mathrm{mM}$ EDTA, $400 \mu \mathrm{g} / \mathrm{ml}$ of proteinase $\mathrm{K}$ ) at $55^{\circ} \mathrm{C}$ overnight. The tubes were boiled for $7 \mathrm{~min}$ to inactivate the proteinase $\mathrm{K}$, and then $1 \mu \mathrm{l}$ of these extracts were used for each polymerase chain reaction (PCR) amplification.

\section{Microsatellite assay}

Six microsatellite markers (BAT-25, BAT-26, D5S346, D17S250, D1S191 and BAT40) were analyzed. The forward primers were fluorescein labeled with [6-FAM] (D1S191, D17S250, BAT-26 and BAT-40), [VIC] (D5S346) and [TAMRA] (BAT-25). PCR was performed in total $15 \mu \mathrm{l}$ reaction volumes containing $1 \mu \mathrm{l}$ template DNA, $0.56 \mu \mathrm{mol} / 1$ of each primer, $74.7 \mu \mathrm{mol} / 1$ of dATP, dGTP, dCTP and dTTP, respectively, $4.5 \mathrm{mmol} / 1$ of $\mathrm{MgCl}_{2}$ and $0.075 \mathrm{U}$ of AmpliTaq Gold (Applied Biosystems, Foster City, CA). The PCR amplification consisted of 45 cycles $\left(94^{\circ} \mathrm{C}\right.$ for $45 \mathrm{~s}, 55^{\circ} \mathrm{C}$ for $45 \mathrm{~s}$ and $72^{\circ} \mathrm{C}$ for $45 \mathrm{~s}$ ) after the initial Taq DNA polymerase activation step $\left(95^{\circ} \mathrm{C}\right.$ for $\left.10 \mathrm{~min}\right)$, followed by a final extension for $10 \mathrm{~min}$ at $72^{\circ} \mathrm{C}$. PCR products were electrophoresed in ABI PRISM 310 Genetic Analyzer along with GeneScan-500 [ROX] molecular weight standard (Applied Biosystems). The size of the PCR product was analyzed using GeneScan software (Applied Biosystems). Tumors were characterized as MSI $(+)(=$ MSI-high) if two or more of the markers showed instability. When one or none of the markers showed instability, tumors were designated as MSI (-) (= MSS/MSIlow). We considered MSS (microsatellite stable) and MSI-low cases together as MSI (-) because there was no statistical difference between them [17].

\section{Immunohistochemistry}

Immunohistochemistry was performed on formalin-fixed, paraffin-embedded sections using a streptavidin-biotin system (Dakocytomation, Copenhagen, Denmark). Mouse monoclonal antibody to hMLH1 (diluted 1:100), (Pharmingen, San Diego, CA) was used after antigen retrieval by microwave. Slides were counterstained with Meyer's haematoxylin. The evaluation of hMLH1 immunoreativity was categorized as positive or negative. Cases with definite nuclear staining in more than $30 \%$ of the tumor cells were categorized as positive and those with definite nuclear staining less than $30 \%$ of the tumor cells as negative.

\section{Bisulfite modification and methylation-specific PCR (MSP)}

The methylation status of the $\mathrm{CpG}$ island in the promoter region of $h M L H 1, M G M T, p 16$ and E-cadherin was determined by bisulfite treatment of DNA followed by methylationspecific PCR with some modifications [18]. In brief, $2 \mu \mathrm{g}$ of microdissected genomic DNA was denatured by treatment with $\mathrm{NaOH}$ and modified with $3 \mathrm{M}$ sodium bisulfite for $16 \mathrm{~h}$. DNA samples were purified with Wizard DNA 
purification resin (Promega, Madison, WI), treated with $\mathrm{NaOH}$, precipitated with ethanol, and resuspended in $20 \mu \mathrm{l}$ of distilled water. The primer sequences of each gene and conditions of the PCRs were in accordance with those of the previous reports [18-20]. Ten $\mu \mathrm{l}$ of PCR products underwent electrophoresis on $8 \%$ non-denaturing polyacrylamide gels, then visualized under UV illumination using an ethidium bromide stain. DNA from Colo320 colon cancer cell line treated with $\mathrm{CpG}$ methyltransferase (New England Biolabs, Beverly, MA) was used as a positive control for methylation and distilled water was used as a negative control.

\section{Statistical analysis}

Data were analyzed using the SPSS software (SPSS Inc., Chicago, IL). Fisher's exact test were used for analysis of most of the categorical or numerical data, respectively. In addition, the cumulative rate of secondary gastric cancer development in patients with MSI $(+)$ gastric cancer and that in patients with MSI (-) gastric cancer were calculated by the Kaplan-Meier method. A $p$ value less than 0.05 was regarded as statistically significant.

\section{Results}

\section{The frequency of MSI}

Representative results of microsatellite analyses are shown in Fig. 1. MSI (+) was detected in 5 of the $14(35.7 \%)$ patients with multiple gastric cancers (MGCs). On the other hand, MSI (+) was only detected in 3 of the $32(9.3 \%)$ patients with solitary gastric cancers (SGC) (Table 1). The frequency of MSI $(+)$ was significantly higher in the patients with multiple gastric cancers than that in those with a single gastric cancer $(p<0.001)$.

There was no statistical difference between SGC and MGC in evaluated clinicopathologic features including age, sex, tumor histology, tumor location or $H$. pylori infection (Table 2).

Promoter hypermethylation of hMLH1, MGMT, p16 and Ecadherin

Representative results of MSP of $h M L H 1, M G M T, p 16$

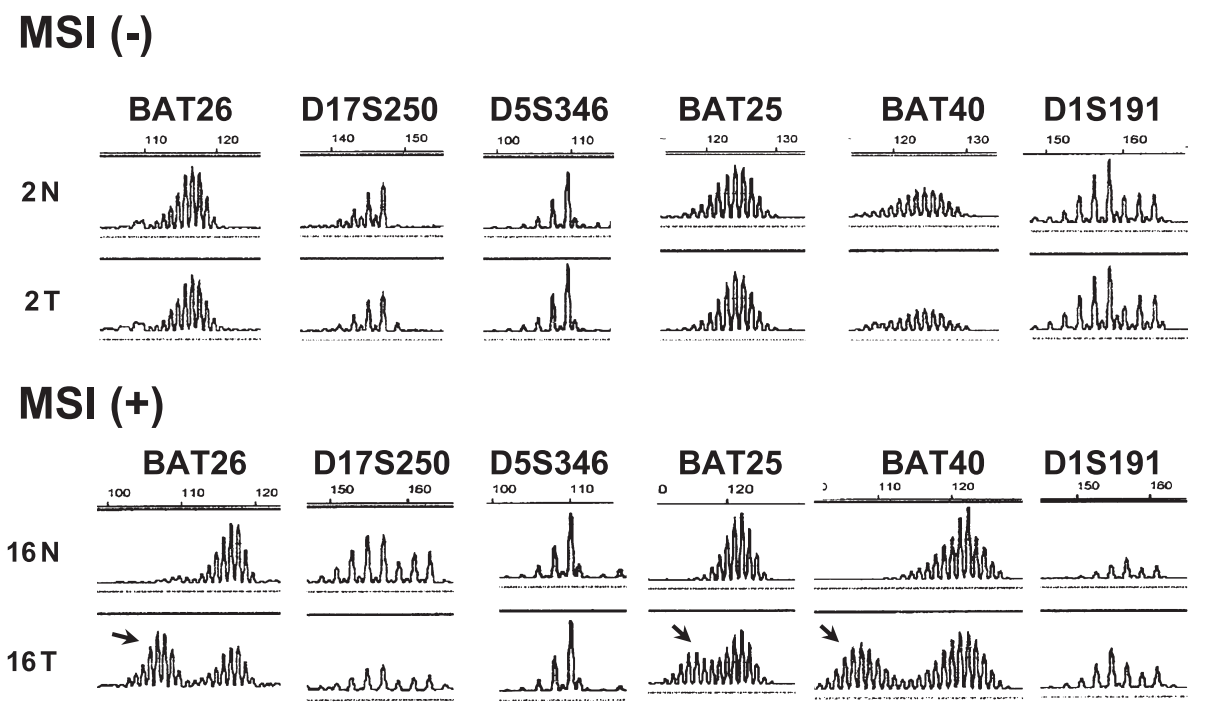

Fig. 1. Representative results of microsatellite analyses in early gastric carcinomas. In case 2 (upper panel), each microsatellite demonstrates identical pattern between normal gastric mucosa $(\mathrm{N})$ and cancer $(\mathrm{T})$. On the other hand, BAT-26, BAT-25 and BAT 40 show extra-peaks (arrows) in cancer DNA from case 16.

Table 1. Comparison of the frequency of microsatellite instability in early multiple gastric cancers and early solitary gastric cancers

\begin{tabular}{lcccc}
\hline & total & MSI $(+)^{\mathrm{a}}(\%)$ & MSI $(-)^{\mathrm{b}}(\%)$ & $p$ value \\
\hline Patients with solitary gastric cancers & 32 & $3(9.3 \%)$ & $29(90.7 \%)$ & $<0.001$ \\
Patients with multiple gastric cancers & 14 & $5(35.7 \%)$ & $9(64.3 \%)$ & \\
Solitary gastric lesions & 32 & $3(9.3 \%)$ & $29(90.7 \%)$ & 0.02 \\
Multiple gastric lesions & 32 & $7(21.9 \%)$ & $25(78.1 \%)$ & \\
\hline
\end{tabular}

${ }^{\text {a }}$ MSI (+); two or more of the markers showed instability

${ }^{\mathrm{b}} \mathrm{MSI}(-)$; one or none of the markers showed instability

Vol. 40, No. 3, 2007 
Table 2. Comparison of clinicopathological factors between early multiple gastric cancers and early solitary gastric cancers

\begin{tabular}{lccc}
\hline & $\begin{array}{c}\text { Solitary } \\
\text { gastric cancer } \\
(n=32 \text { cases })\end{array}$ & $\begin{array}{c}\text { Multiple } \\
\text { gastric cacner } \\
(n=14 \text { cases, } \\
32 \text { lesions })\end{array}$ & $p$ value \\
\hline Age & 67.1 & 71.5 & N.S \\
Sex & & 12 & \\
$\quad$ male & 21 & 2 & N.S \\
female & 11 & 6 & \\
Location & 3 & 6 & N.S \\
U & 8 & 20 & \\
M & 21 & 31 & N.S \\
L & & 1 & \\
Histologic type & 29 & 30 & N.S \\
Well & 3 & 2 & \\
$\quad$ Moderate & & & \\
Depth of invasion & 29 & & \\
m & 3 & & \\
sm & 14 & & \\
Helicobacter pylori & & & \\
Positive & & & \\
\hline N.S.; not significant & & & \\
\hline
\end{tabular}

and E-cadherin are shown in Fig. 2. Table 3 summarizes the frequency of the promoter hypermethylation of each gene in early SGCs and MGCs. Hypermethylation of $h M L H 1$ was more frequently observed in MGCs than in SGCs $(p<0.01)$, whereas significant difference was not observed in the frequency of $M G M T, p 16$ and E-cadherin promoter methylation between the 2 groups.

Relationship between promoter hypermethylation and MSI

Next, we compared the frequency of $h M L H 1, M G M T, p 16$ and E-cadherin promoter methylation and microsatellite status in the early gastric cancers (Fig. 3). Methylation of $h M L H 1$ was present in $70 \%(7 / 10)$ of MSI $(+)$ tumors and in $14.8 \%(8 / 54)$ of MSI $(-)$ tumors $(p<0.01)$. Methylation of MGMT was detected in 70\% (7/10) of MSI $(+)$ tumors and in $33.3 \%(18 / 54)$ of MSI $(-)$ tumors $(p<0.01)$. Methylation of $E$-cadherin was present in $30 \%(3 / 10)$ of MSI $(+)$ tumors and in $18.5 \%(10 / 54)$ of MSI $(-)$ tumors $(p=0.058)$. Methylation of $p 16$ was present in $50 \%(5 / 10)$ of MSI $(+)$ tumors and in $18.5 \%(10 / 54)$ of MSI $(-)$ tumors $(p<0.01)$.

\section{Relationship between promoter hypermethylation and expression of $h M L H 1$}

Finally, we analyzed the relationship between promoter hypermethylation of $h M L H 1$ and its expression (Table 4). Of 15 gastric cancers with promoter methylation of $h M L H 1$ gene, $10(66.7 \%)$ showed absent or decreased hMLH1 expression. In contrast, 40 of 49 gastric cancers $(81.6 \%)$ without $h M L H 1$ gene methylation showed intense nuclear immunoreactivity of hMLH1. Absent or decreased hMLH1 expression was significantly correlated with promoter hypermethylation of the gene $(p<0.001)$. In addition, $h M L H 1$ promoter hypermethylation was detected in 70\% (7/10) of MSI $(+)$ tumors and was associated with absent or decreased hMLH1 expression in all 7 cases. In contrast, 8 of 54 (14.8\%) MSI (-) tumors demonstrated $h M L H 1$ promoter hypermethylation. Five of these cases showed normal nuclear immunoreactivity of hMLH1.

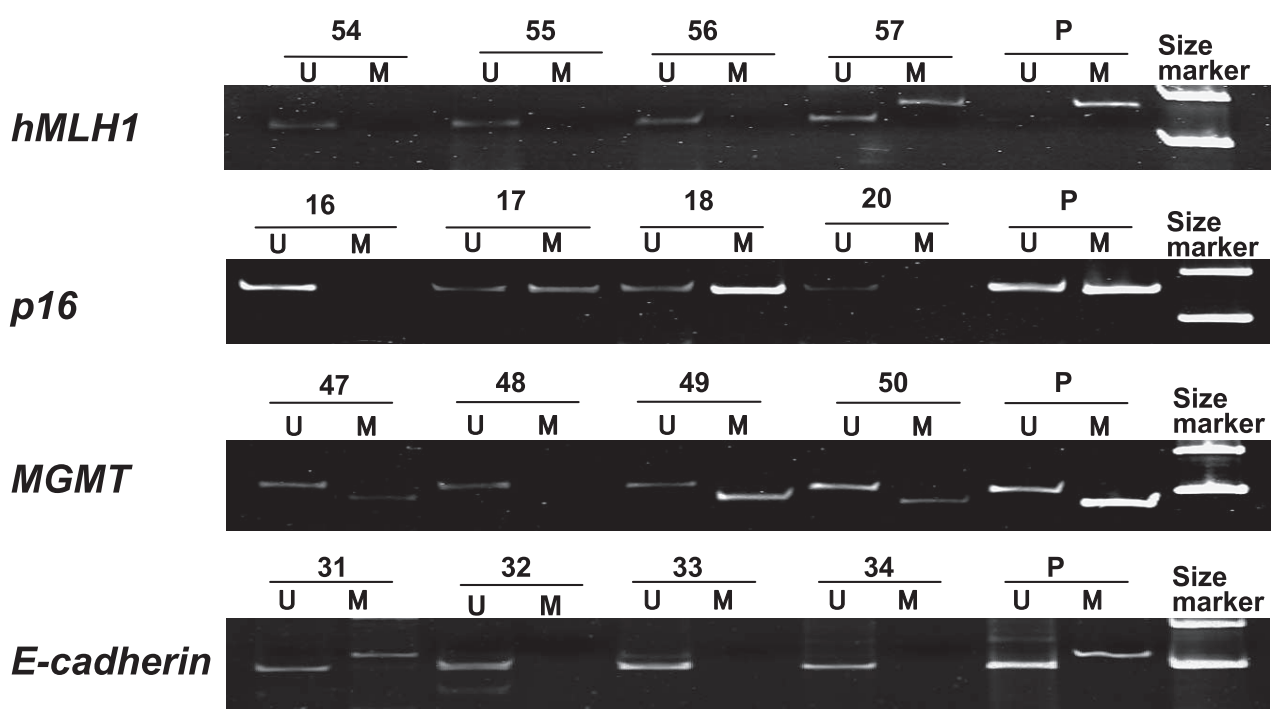

Fig. 2. Representative results of methylation-specific PCR of $h M L H 1, p 16, M G M T$ and E-cadherin by using both methylated (M) and unmethylated (U) specific primers in gastric cancer. Methylated PCR products were detected in case 57 for $h M L H 1$, in case 17 and 18 for $p 16$, in case 47, 49 and 50 for MGMT and in case 31 for E-cadherin. P, positive control. 
Table 3. Methylation frequencies and number of methylated genes in early multiple gastric cancers and early solitary gastric cancers

\begin{tabular}{|c|c|c|c|c|}
\hline & & $\begin{array}{c}\text { Solitary } \\
\text { gastric cancers } \\
n=32(\%)\end{array}$ & $\begin{array}{c}\text { Multiple } \\
\text { gastric cacners } \\
n=32(\%)\end{array}$ & $p$ value \\
\hline \multirow[t]{2}{*}{$h M L H 1$} & Unmethylated (\%) & $27(84.4)$ & $22(68.7)$ & \multirow{2}{*}{$<0.01$} \\
\hline & Methylated (\%) & $5(15.6)$ & $10(31.3)$ & \\
\hline \multirow[t]{2}{*}{$M G M T^{\mathrm{a}}$} & Unmethylated (\%) & $19(59.4)$ & $20(62.5)$ & \multirow{2}{*}{0.653} \\
\hline & Methylated (\%) & $13(40.6)$ & $12(37.5)$ & \\
\hline \multirow[t]{2}{*}{ p16 } & Unmethylated (\%) & $25(78.1)$ & $24(75.0)$ & \multirow{2}{*}{0.605} \\
\hline & Methylated (\%) & $7(21.9)$ & $8(25.0)$ & \\
\hline \multirow[t]{2}{*}{ E-cadherin } & Unmethylated (\%) & $25(78.1)$ & $26(81.2)$ & \multirow{2}{*}{0.586} \\
\hline & Methylated (\%) & 7 (21.9) & $6(18.8)$ & \\
\hline
\end{tabular}

a MGMT, $\mathrm{O}^{6}$-methylguanine DNA methylyransferase

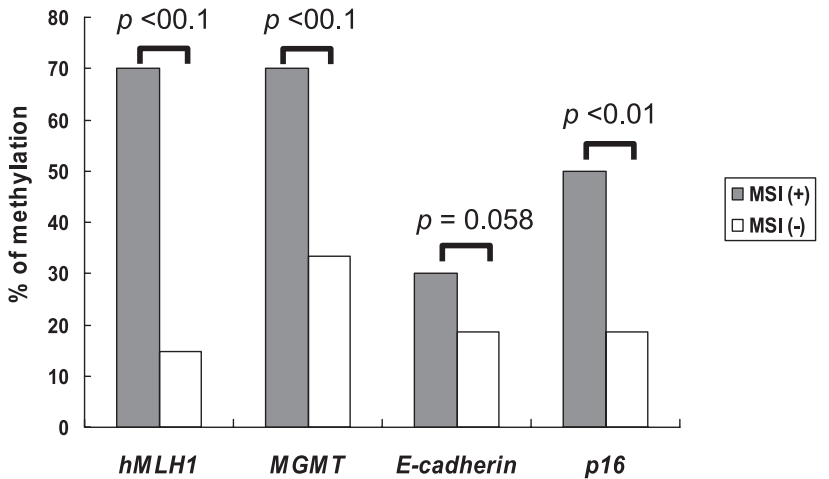

Fig. 3. Comparison of the frequency of the promoter hypermethylation of $h M L H 1, M G M T, p 16$ and E-cadherin in MSI (+) and MSI (-) gastric cancers. The incidences of promoter hypermethylation of $h M L H 1, M G M T$ and $p 16$ are significantly higher in the MSI $(+)$ tumors than in the MSI ( - ) tumors. On the other hand, significant difference is not observed in the frequency of $E$ cadherin promoter methylation between the 2 groups.

Table 4. Correlation with promoter methylation status and protein expression of $h M L H 1$ in gastric cancers

\begin{tabular}{|c|c|c|c|}
\hline \multirow{2}{*}{$\begin{array}{l}h M L H 1 \text { gene promoter } \\
\text { status }\end{array}$} & \multirow{2}{*}{ Total } & \multicolumn{2}{|c|}{ hMLH1 immunoreactivity } \\
\hline & & Positive (\%) & Negative (\%) \\
\hline Methylated & 15 & $5(33.3)$ & $10(66.7)$ \\
\hline Unmethylated & 49 & $40(81.6)$ & $9(18.4)$ \\
\hline
\end{tabular}

a Significant difference $(p<0.001)$ by Fisher's exact test

\section{Discussion}

This is the first report to evaluate the MSI status and hypermethylation of several tumor-related genes in MGCs of patients treated with EMR. We demonstrated that the frequency of MSI (+) was significantly higher in the patients with MGCs than those with SGCs and that hypermethylation of $h M L H 1$ was more frequently detected in MGCs than in SGCs $(p<0.01)$. Therefore, MSI $(+)$ and hypermethylation of hMLH1 may serve as a useful marker for identifying individuals who may be at risk of developing MGCs.

By the development of the endoscopic therapeutic techniques, endoscopic resection can cure most of the early gastric cancers. However, because the background gastric mucosa in such cases are accompanied by chronic gastritis and intestinal metaplasia, development of metachronous multiple gastric cancers in other sites is a major problem. Uemura et al. [3] reported that no new gastric cancer cases were detected for 2 years in patients treated with $H$. pylori eradication after the resection of the first cancer and on the other hand, $9 \%$ of the patients with $H$. pylori had metachronous early gastric cancer in other site. Park et al. [21] reported that the expression of DNA mismatch repair proteins increased in the gastric mucosa after $H$. pylori eradication. Chan et al. [22] showed disappearing of $E$-cadherin promoter hypermethylation status after $H$. pylori eradication in patients with chronic gastritis. If $H$. pylori eradication therapy may reverse methylation of tumor suppressor or tumor-related genes, early reversal of promoter methylation at the residual gastric mucosa in the patients treated with EMR may prevent the development of metachronous gastric cancer. This indicates the possibility of useful targeting therapy. It is very valuable to find tumor suppressor or tumor-related genes that have been methylated in the MGCs of the patients treated with EMR.

Based on previous reports [9-13], we selected four genes (hMLH1, MGMT, E-cadherin, p16) and examined the methylation status of these genes in the present study. Hypermethylation of $h M L H 1$ was more frequently detected in MGCs than in SGCs $(p<0.01)$, whereas significant difference was not observed in the frequency of $M G M T$, $p 16$ or E-cadherin promoter methylation between the 2 groups. Regarding $h M L H 1$, it is known that hypermethylation of its 
promoter region leads to diminished protein expression and is significantly associated with genome-wide instability of simple repeat sequences, referred to as $\operatorname{MSI}(+)[9,12,15,20]$. In the present study, absent or decreased hMLH1 expression was significantly correlated with promoter hypermethylation of the gene by immunohistochemistry. In addition, $h M L H 1$ promoter hypermethylation was detected in $70 \%$ of MSI $(+)$ tumors and was associated with absent or decreased hMLH1 expression in all these cases. In contrast, $14.8 \%$ of MSI (-) tumors demonstrated $h M L H 1$ promoter hypermethylation. Inactivation of hMLH1 through promoter hypermethylation may cause MGCs following the MSI pathway.

There were some reports about MSI or hypermethylation of tumor-related genes in multiple gastric cancers [14-16]. Miyoshi et al. [14] showed that the frequency of MSI was significantly higher in the patients with multiple gastric cancers, both synchronous and metachronous, than in those with a single gastric cancer. Kawamura et al. [16] have reported that thirty percent of patients with metachronous recurrence of gastric cancer after undergoing successful endoscopic resection showed MSI, whereas none of the patients with nonrecurrent disease did so. However, in these two reports, they did not examine the methylation status of tumor-related genes in multiple gastric cancers. Sakata et al. found that hypermethylation of the $h M L H 1$ promoter was detected in all of SGCs and MGCs with MSI [15]. They focused on aberrant methylation in a single gene and their samples were obtained at the time of surgery including only synchronous multiple gastric cancers. No reports have found the correlation between the presence of MSI and various kinds of hypermethylation of tumor-related genes in metachronous multiple gastric cancers.

We also investigated the relationship between the hypermethylation of the promoters of four genes ( $h M L H 1$, MGMT, E-cadherin, p16) and MSI. Significant association was detected between promoter hypermethylation of these three genes except $E$-cadherin and MSI $(+)$ cancers $(p<0.01)$. Some previous reports found that significant associations were found between $h M L H 1$ promoter hypermethylation and MSI $(+)$ cancers in different organs [23-25]. In gastric cancer, Toyota et al. [9] showed that cases showing methylation at more than three of the five loci (methylated in tumors (MINT) 1, 2, 12, 25 and 31) were designated as CpG island methylator phenotype (CIMP) positive, and such CIMP (+) gastric cancers accompanied with the methylation of known genes, including $p 16$ and $h M L H 1$. According to these findings, $\mathrm{CpG}$ island methylation may precede the development of MSI and methylation of some genes may occur in absence of MSI in many tumors. The results of the present study indicates that methylation of $h M L H 1, M G M T$, and $p 16$ may be involved in the development of MSI, and also play a crucial role in early gastric carcinogenesis. The overall frequency of $E$-cadherin promoter hypermethylation in early gastric carcinomas in the present study was $20.3 \%(13 / 64)$, which was lower than those previously reported [18, 26, 27]. Tamura et al. [28] showed that E-cadherin promoter hypermethylation occurred more frequently in carcinomas of the undifferentiated scattered type than in other histological subtypes. The tumors analyzed in this study were histologically differentiated adenocarcinomas comprising early cancers (depth of invasion limited to the mucosa or submucosa). This may affect the frequency of $E$-cadherin promoter methylation in this study. If further examination of large sample size is done, methylation of $M G M T$ and p16, not E-cadherin in early gastric cancer may be a useful molecular marker for the prediction of MGC development.

In conclusion, $h M L H 1$ may be one of the frequent methylation targets in MGCs and its inactivation through promoter hypermethylation may cause MGCs following the MSI pathway. MSI (+) and $h M L H 1$ methylation in gastric cancer may be a useful molecular marker for the prediction of MGC development and these patients will need to be closely observed by endoscopy as high risk patients even if the treatment with EMR were successful. We also put our hopes in developing some gene-targeting therapies that may reverse methylation at the residual gastric mucosa in the patients treated with EMR in order to prevent the development of metachronous gastric cancer.

\section{References}

[1] Wittekind, C., Klimpfinger, M., Hermanek, P., and Tannapfel, A.: Multiple simultaneous gastric carcinomas. Br. J. Cancer, 76, 1604-1609, 1997.

[2] Kodera, Y., Yamamura, Y., Torii, A., Uesaka, K., Hirai, T., Yasui, K., Morimoto, T., Kato, T., and Kito, T.: Incidence, diagnosis and significance of multiple gastric cancer. Br. J. Surg., 82, 1540-1543, 1995.

[3] Uemura, N., Mukai, T., Okamoto, S., Yamaguchi, S., Mashiba, H., Taniyama, K., Sasaki, N., Haruma, K., Sumii, K., and Kajiyama, G.: Effect of Helicobacter pylori eradication on subsequent development of cancer after endoscopic resection of early gastric cancer. Cancer Epidemiol. Biomarkers Prev., 6, 639-642, 1997.

[4] Aaltonen, L.A., Peltomaki, P., Leach, F.S., Sistonen, P., Pylkkanen, L., Mecklin, J.P., Jarvinen, H., Powell, S.M., Jen, J., Hamilton, S.R., Petersen, G.M., Kinzler, K.W., Vogelstein, B., and de la Chapelle, A.: Clues to the pathogenesis of familial colorectal cancer. Science, 260, 812-816, 1993.

[5] Ionov, Y., Peinado, M.A., Malkhosyan, S., Shibata, D., and Perucho, M.: Ubiquitous somatic mutations in simple repeated sequences reveal a new mechanism for colonic carcinogenesis. Nature, 363, 558-561, 1993.

[6] Thibodeau, S.N., French, A.J., Roche, P.C., Cunningham, J.M., Tester, D.J., Lindor, N.M., Moslein, G., Baker, S.M., Liskay, R.M., Burgart, L.J., Honchel, R., and Halling, K.C.: Altered expression of hMSH2 and hMLH1 in tumors with microsatellite instability and genetic alterations in mismatch 
repair genes. Cancer Res., 56, 4836-4840, 1996.

[7] Baylin, S.B., Herman, J.G., Graff, J.R., Vertino, P.M., and Issa, J.P.: Alterlations in DNA methylation: fundamental aspect of neoplasia. Adv. Cancer Res., 72, 141-196, 1998.

[8] Jones, P.A. and Laird, P.W.: Cancer epigenetics comes of age. Nature Genet., 21, 163-167, 1999.

[9] Toyota, M., Ahuja, N., Suzuki, H., Itoh, F., Ohe-Toyota, M., Imai, K., Baylin, S.B., and Issa, J.P.: Aberrant methylation in gastric cancer associated with $\mathrm{CpG}$ island methylator phenotype. Cancer Res., 59, 5438-5442, 1999.

[10] Suzuki, H., Itoh, F., Toyota, M., Kikuchi, T., Kakiuchi, H., Hinoda, Y., and Imai, K.: Distinct methylation pattern and microsatellite instability in sporadic gastric cancer. Int. J. Cancer, 83, 309-313, 1999.

[11] Lee, J.H., Park, S.J., Abraham, S.C., Seo, J.S., Nam, J.H., Choi, C., Juhng, S.W., Rashid, A., Hamilton, S.R., and Wu, T.T.: Frequent $\mathrm{CpG}$ island methylation in precursor lesions and early gastric adenocarcinomas. Oncogene, 23, 46464654, 2004.

[12] Fleisher, A.S., Esteller, M., Wang, S., Tamura, G., Suzuki, H., Yin, J., Zou, T.T., Abraham, J.M., Kong, D., Smolinski, K.N., Shi, Y.Q., Rhyu, M.G., Powell, S.M., James, S.P., Wilson, K.T., Herman, J.G., and Meltzer, S.J.: Hypermethylation of the $h M L H 1$ gene promoter in human gastric cancers with microsatellite instability. Cancer Res., 59, 1090-1095, 1999.

[13] Kang, G.H., Shim, Y.H., Jung, H.Y., Kim, W.H., Ro, J.Y., and Rhyu, M.G.: CpG island methylation in premalignant stages of gastric carcinoma. Cancer Res., 61, 2847-2851, 2001.

[14] Miyoshi, E., Haruma, K., Hiyama, T., Tanaka, S., Yoshihara, M., Shimamoto, F., and Chayama, K.: Microsatellite instability is a genetic marker for the development of multiple gastric cancers. Int. J. Cancer, 95, 350-353, 2001.

[15] Sakata, K., Tamura, G., Endoh, Y., Ohmura, K., Ogata, S., and Motoyama, T.: Hypermethylation of the hMLH1 gene promoter in solitary and multiple gastric cancers with microsatellite instability. Br. J. Cancer, 86, 564-567, 2002.

[16] Kawamura, A., Adachi, K., Ishihara, S., Katsube, T., Takashima, T., Yuki, M., Amano, K., Fukuda, R., Yamashita, Y., and Kinoshita, Y: Correlation between microsatellite instability and metachronous disease recurrence after endoscopic mucosal resection in patients with early stage gastric carcinoma. Cancer, 91, 339-345, 2001.

[17] Hawkins, N., Norrie, M., Cheong, K., Mokany, E., Ku, S.L., Meagher, A., O'Connor, T., and Ward, R.: CpG island methylation in sporadic colorectal cancers and its relationship to microsatellite instability. Gastroenterology, 122, 1376-1387, 2002.

[18] Herman, J.G., Graff, J.R., Myohanen, S., Nelkin, B.D., and Baylin, S.B.: Methylation-specific PCR. A novel PCR assay for methylation status of $\mathrm{CpG}$ islands. Proc. Natl. Acad. Sci. USA, 93, 9821-9826, 1996.

[19] Esteller, M., Gaidano, G., Goodman, S.N., Zagonel, V.,
Capello, D., Botto, B., Rossi, D., Gloghini, A., Vitolo, U., Carbone, A., Baylin, S.B., and Herman, J.G.: Hypermethylation of the DNA repair gene $O^{6}$-methylguanine DNA methyltransferase and survival of patients with diffuse large B-cell lymphoma. J. Natl. Cancer Inst., 94, 26-32, 2002.

[20] Kang, G.H., Shim, Y.H., and Ro, J.Y.: Correlation of methylation the $h M L H 1$ promoter with lack of expression of hMLH1 in sporadic gastric carcinomas with replication error. Lab. Invest., 79, 903-909, 1999.

[21] Park, D.I., Park, S.H., Kim, S.H., Kim, J.W., Cho, Y.K., Kim, H.J., Sohn, C.I., Jeon, W.K., Kim, B.I., Cho, E.Y., Kim, E.J., Chae, S.W., Sohn, J.H., Sung, I.K., Sepulveda, A.R., and Kim, J.J.: Effect of Helicobacter pylori infection on the expression of DNA mismatch repair protein. Helicobacter, 10, 179-184, 2005.

[22] Chan, A.O., Peng, J.Z., Lam, S.K., Lai, K.C., Yuen, M.F., Cheung, H.K., Kwong, Y.L., Rashid, A., Chan, C.K., and Wong, B.C.: Eradication of Helicobacter pylori infection reverses E-cadherin promoter hypermethylation. Gut, 55, 463-468, 2006.

[23] Herman, J.G., Umar, A., Polyak, K., Graff, J.R., Ahuja, N., Issa, J.P., Markowitz, S., Willson, J.K., Hamilton, S.R., Kinzler, K.W., Kane, M.F., Kolodner, R.D., Vogelstein, B., Kunkel, T.A., and Baylin, S.B.: Incidence and functional consequences of $h M L H 1$ promoter hypermethylation in colorectal carcinoma. Proc. Natl. Acad. Sci. USA, 95, 68706875, 1998.

[24] Esteller, M., Levine, R., Baylin, S.B., Ellenson, L.H., and Herman, J.G.: $h M L H 1$ promoter hypermethylation is associated with the microsatellite instability phenotype in sporadic endometrial carcinomas. Oncogene, 17, 2413-2417, 1998.

[25] Fleisher, A.S., Esteller, M., Wang, S., Tamura, G., Suzuki, H., Yin, J., Zou, T.T., Abraham, J.M., Kong, D., Smolinski, K.N., Shi, Y.Q., Rhyu, M.G., Powell, S.M., James, S.P., Wilson, K.T., Herman, J.G., and Meltzer, S.J.: Hypermethylation of the $h M L H 1$ gene promoter in human gastric cancers with microsatellite instability. Cancer Res., 59, 1090-1095, 1999.

[26] Carvalho, B., Pinto, M., Cirnes, L., Oliveira, C., Machado, J.C., Suriano, G., Hamelin, R., Carneiro, F., and Seruca, R.: Concurrent hypermethylation of gene promoters is associated with a MSI-H phenotype and diploidy in gastric carcinomas. Eur. J. Cancer, 39, 1222-1227, 2003.

[27] Leung, W.K., Yu, J., Ng, E.K., To, K.F., Ma, P.K., Lee, T.L., Go, M.Y., Chung, S.C., and Sung, J.J.: Concurrent hypermethylation of multiple tumor-related genes in gastric carcinoma and adjacent normal tissues. Cancer, 91, 2294-2301, 2001.

[28] Tamura, G., Yin, J., Wang, S., Fleisher, A.S., Zou, T., Abraham, J.M., Kong, D., Smolinski, K.N., Wilson, K.T., James, S.P., Silverberg, S.G., Nishizuka, S., Terashima, M., Motoyama, T., and Meltzer, S.J.: E-cadherin gene promoter hypermethylation in primary human gastric carcinomas. J. Natl. Cancer Inst., 92, 569-573, 2000. 